\title{
Prognostic role of the long non-coding RNA metastasis-associated lung adenocarcinoma transcript 1 in various cancers: A meta-analysis
}

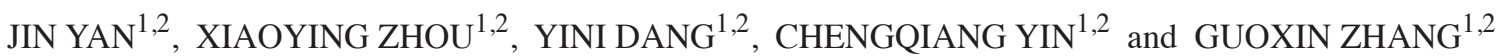 \\ ${ }^{1}$ Department of Gastroenterology, The First Affiliated Hospital of Nanjing Medical University; \\ ${ }^{2}$ The First School of Clinical Medicine of Nanjing Medical University, Nanjing, Jiangsu 210029, P.R. China
}

Received April 20, 2015; Accepted September 18, 2015

DOI: $10.3892 / \operatorname{mco} .2015 .657$

\begin{abstract}
Several studies have investigated the correlation between the expression of metastasis-associated lung adenocarcinoma transcript 1 (MALAT1) and cancer prognosis, with inconsistent results. Therefore, a meta-analysis was conducted to identify the potential correlation after pooling data from eligible studies. PubMed/Medline, Web of Science and The Cochrane Library electronic databases were searched for eligible studies on the prognostic role of MALAT1 in cancer, from inception to January, 2015. Pooled hazard ratios (HRs) with $95 \%$ confidence intervals (CIs) were calculated to summarize the effect. A total of 1,198 patients from 10 studies were included in the analysis. The results suggested that MALAT1 expression was significantly associated with overall survival ( $\mathrm{HR}=2.07,95 \% \mathrm{CI}: 1.67-2.56)$, disease-free survival $(\mathrm{HR}=2.60,95 \% \mathrm{CI}: 1.69-4.00)$ and recurrence-free survival (HR=3.28, 95\% CI: 1.52-7.09). MALAT1 was also found to be significantly associated with tumor size $(\mathrm{P}=0.013)$. Overall, MALAT1 expression may be considered as a potential prognostic factor for cancer patients.
\end{abstract}

\section{Introduction}

The Human Genome Project demonstrated that $\geq 90 \%$ of the human genome is actively transcribed to RNA, but $<2 \%$ of the RNA encodes proteins $(1,2)$. Long non-coding RNAs (lncRNAs) are non-protein-coding RNA molecules longer than 200 nucleotides, which in the past had been simply dismissed as transcriptional 'noise' (3). IncRNAs are highly conserved throughout mammalian evolution, including in

Correspondence to: Dr Guoxin Zhang, Department of Gastroenterology, The First Affiliated Hospital of Nanjing Medical University, 300 Guangzhou Road, Nanjing, Jiangsu 210029, P.R. China

E-mail: guoxinz@njmu.edu.cn

Key words: metastasis-associated lung adenocarcinoma transcript 1, cancer, clinicopathological characteristics, prognosis, meta-analysis humans. In addition, lncRNAs have been shown to be aberrantly expressed in various diseases, including cancer (4). It has been reported that lncRNAs are associated with a spectrum of biological processes, such as gene regulation at the transcriptional and post-transcriptional levels, chromatin modification and epigenetics, protein activity modulation and protein localization $(5,6)$. In fact, lncRNAs have been recognized as hallmarks of the onset and development of various types of cancer $(7,8)$.

Metastasis-associated lung adenocarcinoma transcript 1 (MALAT1), an 8.1-kb lncRNA transcribed from the 52 nuclear-enriched transcript 2, was one of the first cancer-associated lncRNAs to be identified. In terms of its association with cancer, MALAT1 has been shown to be oncogenic and is overexpressed in several types of cancer (9-13). As regards its function, MALAT1 is localized to nuclear speckles and has been associated with a number of cancer-related processes, such as alternative splicing and cell cycle regulation (14-17).

Recent clinical studies have demonstrated that increased expression of MALAT1 is correlated with poor prognosis in various types of cancer. Furthermore, MALAT1 in different human cancers is significantly correlated with certain clinicopathological characteristics, such as cancer differentiation, depth of invasion and lymph node metastasis $(9,18-26)$. However, a number of these studies are limited by their small size and single-center design. Therefore, a meta-analysis was performed to elucidate the prognostic value of MALAT1 in human cancer.

\section{Materials and methods}

Search strategy and selection criteria. The present meta-analysis was performed in line with the guidelines of the Meta-analysis of Observational Studies in Epidemiology and Preferred Reporting Items for Systematic Reviews and Meta-Analyses groups (27,28). The PubMed/Medline, Web of Science and The Cochrane Library databases were systematically searched (up to January, 2015) for articles assessing the prognostic value of MALAT1 in various types of cancer. The key words and related Medical Subject Headings for lncRNA, MALAT1, cancer, prognosis, death and survival were used. 


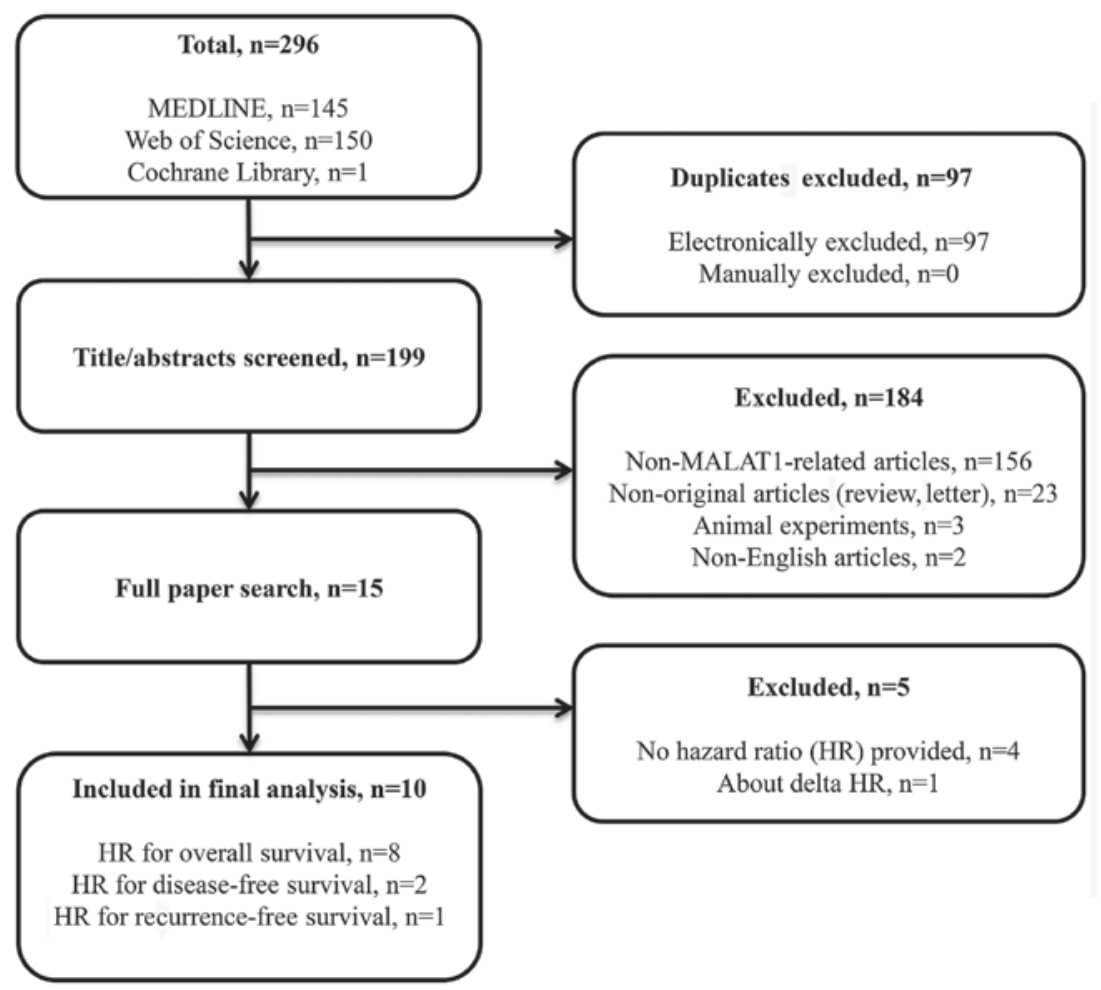

Figure 1. Flow chart of identification process for eligible studies. MALAT1, metastasis-associated lung adenocarcinoma transcript 1.

In addition, experts were consulted, the reference lists of retrieved articles were reviewed, and the 'see related articles' links were searched for key publications in PubMed. In addition, the authors of the articles were contacted if necessary.

The inclusion criteria for the present analysis were as follows: i) Studies investigating the prognostic role of MALAT1 in patients with various types of cancer; ii) providing enough information to estimate hazard ratio (HR) and $95 \%$ confidence interval (CI) for overall survival (OS), disease-free survival (DFS) or recurrence-free survival (RFS); and iii) studies conducted on adults and published in English. Duplicate studies, non-original articles and animal experiments were excluded. Two reviewers (J.Y. and X.Y.Z.) independently scanned all titles and abstracts identified during the search. In addition, we obtained full-text reports of articles that indicated or suggested eligibility, resolving disagreements on exclusion through consensus adjudication. Finally, a total of 10 studies were included in the analysis (14,18-26).

Data extraction and quality assessment. Data were independently extracted by two investigators (J.Y. and X.Y.Z.) trained to interpret information to ensure homogeneity in data collection and entry. These data included name of first author, year of publication, demographic characteristics of the patients included in the study (number, age, gender and ethnicity), cancer characteristics (tumor type, tumor size, differentiation, invasion, lymph node metastasis and stage), study design (specimen, measuring method, cut-off point defining high MALAT1 expression and follow-up period) and survival analysis. HRs were preferentially extracted from multivariate or univariate analyses; if these were not available, Engauge 4.0 was used to calculate HRs and corresponding 95\% CIs.
Study quality was rated by the Newcastle-Ottawa Quality Assessment Scale for Cohort Studies (29), in which the quality of the selected study was determined by 8 questions in 3 domains: selection ( $0-4$ points) and comparability (0-2 points) of the study groups, and ascertainment of the outcome of interest (0-3 points). Based on previous recommendations, studies with 5 points were considered to be of high quality. The two aforementioned investigators independently evaluated the quality of each study. Disagreements were resolved by consensus.

Statistical analysis. Estimates of odds ratios (ORs) and HRs were weighted and pooled using the generic inverse-variance (30). ORs with $95 \%$ CIs were used to estimate the association between MALAT1 expression and clinicopathological characteristics. Pooled HRs with $95 \%$ CIs were used to estimate the prognostic role of MALAT1 in various cancers. $\mathrm{I}^{2}$ was calculated as a measure of statistical heterogeneity, with values of 25,50 and $75 \%$ representing mild, moderate and severe heterogeneity, respectively. Random-effects models were applied in cases with significant heterogeneity. Stratified analyses were conducted to assess potential confounder contribution to heterogeneity. In addition, publication bias was investigated using Begg's funnel plots and Egger's linear regression test. Analyses were performed with STATA statistical software, version 12.0 (Stata Corporation, College Station, TX, USA). The results were considered significant at two-sided P-value of 0.05 .

\section{Results}

Characteristics of included studies. A total of 296 articles were identified during the electronic search through 


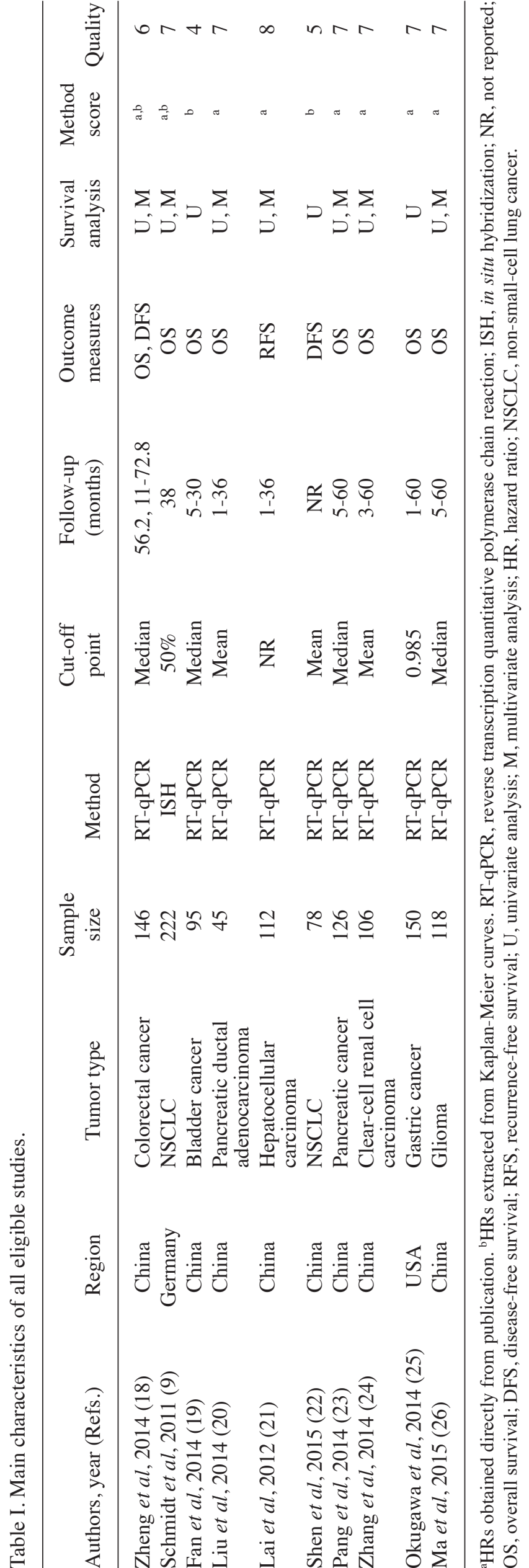

PubMed/Medline, Web of Science and The Cochrane Library. Duplicates, animal experiments, non-MALAT1-related studies, non-English articles, and studies lacking data on the association of MALAT1 expression with prognosis were excluded, leaving 10 eligible studies to be included in this meta-analysis (Fig. 1). The characteristics of the included studies are summarized in Table I. All the studies were published from 2011 onwards. The participants in 8 studies were Chinese and in the other 2 studies German and American. Various types of cancers were recorded, including colorectal, non-small-cell lung and bladder cancer, pancreatic ductal adenocarcinoma, hepatocellular carcinoma, pancreatic cancer, clear cell renal cell carcinoma, gastric cancer and glioma. The expression level of MALAT1 was detected by reverse transcription quantitative polymerase chain reaction or in situ hybridization (ISH). The sample size ranged between 45 and 222 patients. There were 8 studies for OS, 2 for DFS and 1 for RFS. HRs with the corresponding 95\% CIs were extracted from univariate analysis and Kaplan-Meier curves in 10 studies, and from multivariate analysis in 7 studies. The NOS scores of $90 \%$ of the included studies were $\geq 5$.

MALAT1 expression and clinicopathological characteristics. The main results of the association between MALAT1 expression and clinicopathological characteristics are summarized in Table II. The results demonstrated that MALAT1 was not associated with clinicopathological parameters such as age, gender, diffferentiation, depth of invasion, lymph node metastasis, distant metastasis or tumor stage, but was significantly associated with tumor size (HR=2.70, 95\% CI: 1.23-5.92, $\mathrm{P}=0.013)$.

$O S$. A total of 8 studies including 1,008 patients reported HRs for OS. Of the 8 eligible studies, one (12.5\%) reported a non-statistically significant HR (i.e., the 95\% CIs crossed 1). A forest plot of all studies is presented in Fig. 2. It was suggested that increased MALAT1 expression predicted a poor outcome for OS (HR=2.07, 95\% CI: 1.67-2.56, $\mathrm{P}=0.000)$. There appeared to be no heterogeneity between the HRs of MALAT1 among these studies $\left(\mathrm{I}^{2}=0.0 \%, \mathrm{P}=0.488\right)$. However, subgroup analysis was also conducted to investigate the association between HRs and these variables, including type of cancer, region of subjects, sample size, analysis methods and quality scores (Table III). Stratified analysis by cancer type indicated a significant prognostic effect of MALAT1 for digestive (HR=1.86, 95\% CI: 1.37-2.53) and non-digestive system cancers (HR=2.28, 95\% CI: 1.70-3.07). Although the differences in HRs between subjects from China (HR=2.33, 95\% CI: 1.79-3.03) and Western countries $(\mathrm{HR}=1.66$, 95\% CI: 1.16-2.37) was not statistically significant $(\mathrm{P}=0.134)$, high MALAT1 expression in Chinese subjects was associated with numerically higher HR values. Moreover, the HRs were significant for studies including $<110$ subjects $(\mathrm{HR}=2.67$, 95\% CI: $1.69-4.23$ ) as well as those with $>110$ subjects $(\mathrm{HR}=1.93,95 \% \mathrm{CI}: 1.52-2.45)$. When different analysis methods were considered, MALAT1 was a strong prognostic marker by univariate (HR=1.83, 95\% CI: $1.81-2.85)$ as well as multivariate $(\mathrm{HR}=2.15,95 \% \mathrm{CI}: 1.68-2.73)$ analyses. In addition, when performing subgroup analyses stratified by quality score, increased MALAT1 expression was significantly 
Table II. Main results of the meta-analysis of the association between MALAT1 and clinicopathological characteristics.

\begin{tabular}{|c|c|c|c|c|c|c|}
\hline \multirow[b]{2}{*}{ Clinical parameters } & \multirow{2}{*}{$\begin{array}{l}\text { No. of } \\
\text { studies }\end{array}$} & \multicolumn{2}{|c|}{ Fixed-effects model } & \multicolumn{2}{|c|}{ Random-effects model } & \multirow{2}{*}{$\begin{array}{l}\text { Heterogeneity } \\
\qquad\left(\mathrm{I}^{2}\right)(\%)\end{array}$} \\
\hline & & Pooled HR (95\% CI) & P-value & Pooled HR (95\% CI) & P-value & \\
\hline Age (young vs. elderly) & 7 & $1.03(0.77-1.38)$ & 0.854 & $1.03(0.76-1.39)$ & 0.850 & 0.0 \\
\hline Gender (male vs. female) & 7 & $0.62(0.85-1.15)$ & 0.289 & $0.87(0.57-1.33)$ & 0.511 & 41.4 \\
\hline Tumor size (small vs. large) & 6 & $2.46(1.77-3.41)$ & 0.000 & $2.70(1.23-5.92)$ & 0.013 & 79.8 \\
\hline $\begin{array}{l}\text { Differentiation } \\
\text { (high/moderate vs. poor) }\end{array}$ & 4 & $1.27(0.80-2.00)$ & 0.309 & $1.25(0.79-1.98)$ & 0.336 & 0.0 \\
\hline Depth of invasion (T1/2 vs. T3/4) & 3 & $1.88(1.18-3.01)$ & 0.008 & $2.16(0.93-5.02)$ & 0.075 & 63.7 \\
\hline $\begin{array}{l}\text { Lymph node metastasis } \\
\text { (absent vs. present) }\end{array}$ & 5 & $1.85(1.30-2.63)$ & 0.001 & $2.04(0.94-4.45)$ & 0.073 & 76.6 \\
\hline Metastasis (absent vs. present) & 3 & $2.422(1.09-5.37)$ & 0.029 & $3.47(0.36-33.21)$ & 0.280 & 73.3 \\
\hline Stage (I/II vs. III/IV) & 4 & $1.24(0.84-1.84)$ & 0.277 & $1.54(0.56-4.29)$ & 0.407 & 82.3 \\
\hline
\end{tabular}

MALAT1, metastasis-associated lung adenocarcinoma transcript 1; HR, hazard ratio; CI, confidence interval.

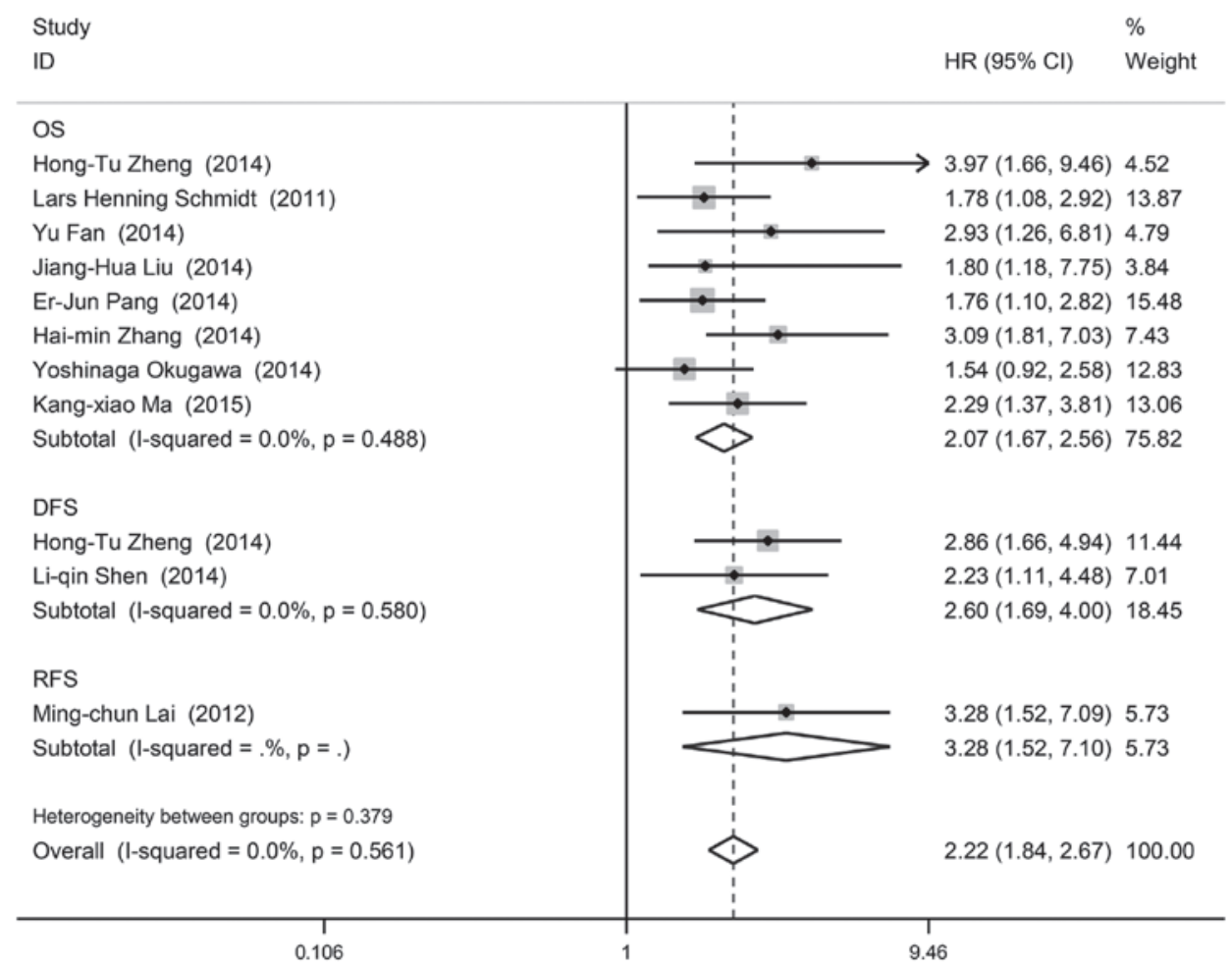

Figure 2. Forest plots for the association between MALAT1 and prognosis in cancer patients by the fixed-effects model. The grey squares indicate the value of OR and the size of the square is inversely proportional to its variance. The horizontal lines represent the 95\% CIs of the ORs. The white diamonds represent the pooled results. MALAT1, metastasis-associated lung adenocarcinoma transcript 1; CI, confidence interval; OR, odds ratio.

associated with poor prognosis in the studies with a score of $<7$ ( $\mathrm{HR}=3.40,95 \% \mathrm{CI}: 1.85-6.22)$, as well as in those with a score of $\geq 7$ (HR=1.93, 95\% CI: $1.54-2.42)$.

Begg's funnel plots and Egger's linear regression tests were applied to evaluate publication bias. The shape of the funnel plot exhibited no significant asymmetry (Fig. 3). Subsequently, Egger's test also indicated no evidence of publication bias $(\mathrm{P}=0.174)$.

DFS and RFS. A total of 2 studies including 224 patients reported HRs for DFS (Table III). Overall, upregulation of MALAT1 was associated with an HR for DFS of 2.60 (95\% CI: 1.69-4.00). In addition, 1 study including 112 patients reported HRs for RFS (Table III). High MALAT1 expression also predicted a poor clinical outcome for $\mathrm{RFS}(\mathrm{HR}=3.28$, 95\% CI: 1.52-7.09).

\section{Discussion}

As a novel molecular basis, the study of lncRNAs has focused on their role in cancer pathogenesis and prognosis, providing a new insight into cancer therapeutic strategy $(31,32)$. This 
Table III. Main results of the pooled analysis.

\begin{tabular}{|c|c|c|c|c|c|c|c|c|c|c|}
\hline \multirow[b]{2}{*}{ Survival } & \multirow[b]{2}{*}{ Variables } & \multirow{2}{*}{$\begin{array}{l}\text { No. of } \\
\text { studies }\end{array}$} & \multirow{2}{*}{$\begin{array}{c}\text { No. of } \\
\text { patients }\end{array}$} & \multirow[b]{2}{*}{$\mathrm{Ps}^{\mathrm{a}}$} & \multicolumn{2}{|c|}{ Fixed-effects model } & \multicolumn{2}{|c|}{ Random-effects model } & \multicolumn{2}{|c|}{ Heterogeneity } \\
\hline & & & & & Pooled HR (95\% CI) & $\mathrm{Pz}^{\mathrm{b}}$ & Pooled HR (95\% CI) & $\mathrm{Pz}^{\mathrm{b}}$ & $\mathrm{I}^{2}(\%)$ & $\mathrm{Ph}^{\mathrm{c}}$ \\
\hline \multirow[t]{16}{*}{ OS } & All & 8 & 1,008 & & $2.07(1.67-2.56)$ & 0 & $2.07(1.67-2.56)$ & 0 & 0.00 & 0.488 \\
\hline & Type of cancer & & & 0.345 & & & & & & \\
\hline & Digestive & 4 & 467 & & $1.86(1.37-2.53)$ & 0 & $1.89(1.35-2.65)$ & 0 & 14.20 & 0.321 \\
\hline & Non-digestive & 4 & 541 & & $2.28(1.70-3.07)$ & 0 & $2.28(1.70-3.07)$ & 0 & 0.00 & 0.559 \\
\hline & Region & & & 0.134 & & & & & & \\
\hline & China & 6 & 636 & & $2.33(1.79-3.03)$ & 0 & $2.33(1.79-3.03)$ & 0.005 & 0.00 & 0.542 \\
\hline & Western countries & 2 & 372 & & $1.66(1.16-2.37)$ & 0.005 & $1.66(1.16-2.37)$ & 0.005 & 0.00 & 0.691 \\
\hline & Sample size & & & 0.221 & & & & & & \\
\hline & $<110$ & 3 & 246 & & $2.67(1.69-4.23)$ & 0 & $2.67(1.69-4.23)$ & 0 & 0.00 & 0.638 \\
\hline & $\geq 110$ & 5 & 762 & & $1.93(1.52-2.45)$ & 0 & $1.93(1.52-2.46)$ & 0 & 1.40 & 0.399 \\
\hline & Analysis method & & & 0.541 & & & & & & \\
\hline & Univariate & 2 & 245 & & $1.83(1.81-2.85)$ & 0.007 & $1.94(1.06-3.55)$ & 0.032 & 38.50 & 0.202 \\
\hline & Multivariate & 6 & 763 & & $2.15(1.68-2.73)$ & 0 & $2.15(1.68-2.73)$ & 0 & 0.00 & 0.486 \\
\hline & Quality score & & & 0.087 & & & & & & \\
\hline & $<7$ & 2 & 241 & & $3.40(1.85-6.22)$ & 0 & $3.40(1.85-6.22)$ & 0 & 0.00 & 0.623 \\
\hline & $\geq 7$ & 6 & 767 & & $1.93(1.54-2.42)$ & 0 & $2.07(1.67-2.56)$ & 0 & 0.00 & 0.658 \\
\hline DFS & All & 2 & 224 & & $2.60(1.69-4.00)$ & 0 & $2.60(1.69-4.00)$ & 0 & 0.00 & 0.58 \\
\hline RFS & All & 1 & 112 & & $3.28(1.52-7.09)$ & & & & & \\
\hline
\end{tabular}

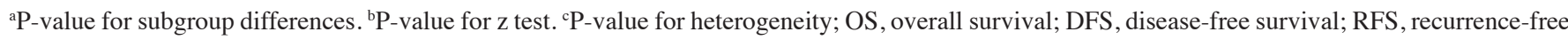
survival; HR, hazard ratio; CI, confidence interval.
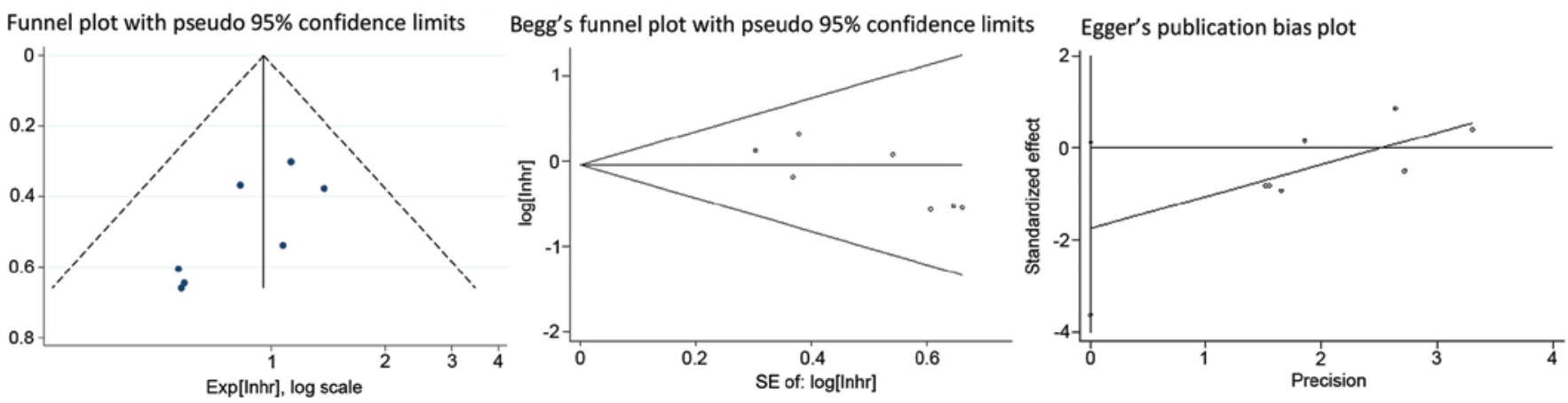

Figure 3. Begg's and Egger's funnel plots of the included literature for OS. The middle line represents the summary estimate, whereas the sloping lines represent the expected $95 \%$ CIs. OS, overall survival; CI, confidence interval; SE, standard error.

meta-analysis was conducted to investigate the effect of lncRNA MALAT1 on tumor prognosis.

A meta-analysis of 10 studies including 1,198 cancer patients was undertaken. We found that increased MALAT1 expression was significantly associated with poorer OS, DFS and RFS, indicating that MALAT1 may be a promising prognostic marker for cancer patients. Moreover, the significant association was retained among various cancer type subgroups and across different regions, sample sizes, analysis methods and quality scores. Our subgroup analysis by region revealed that the abnormal expression of MALAT1 was strongly correlated with poor prognosis in China, as well as in Western countries. There was a trend for the association of high
MALAT1 expression with worse OS to be more significant in the more sensitive and accurate multivariate studies compared with univariate analysis; however, the magnitude of its effect on OS was lower in the subgroup with $>100$ participants and in that with a quality score of $>7$. This contradiction indicates that more studies including more participants are required. In addition, we identified an association between MALAT1 and clinicopathological characteristics, which demonstrated that high MALAT1 expression was significantly correlated with tumor size in the random-effects model and TNM stage in the fixed-effects model. Both Begg's and Egger's tests revealed no significant publication bias regarding the prognostic role of MALAT1 in different types of cancer. 
The mechanisms underlying the association of high MALAT1 expression and poor outcome of cancer patients are poorly understood. The results of this study may suggest the following mechanisms as being potentially involved in the prognostic effect of MALAT1 on carcinogenesis: MALAT1, acting as an oncogene, has been reported to be involved in the modulation of cellular processes leading to tumor occurrence, development, metastasis and drug resistance $(13,22,25,33,34)$. MALAT1 is retained in the nucleus and controls sequestration of the paraspeckle proteins PSP1, p54, and factors linked to A-I editing, which are implicated in mRNA nuclear retention (35); in addition, it has been proven to participate in the phosphatidylinositol 3-kinase/Akt (36), extracellular signal-regulated kinase/mitogen-activated protein kinase (37) and Wnt/ $\beta$-catenin (38) pathways. Downregulating MALAT1 by short hairpin RNA in the CaSki cervical cancer cell line led to a decrease of apoptosis-inhibited gene Bcl-2 and Bcl-xL expression and an increase of apoptosis-promoted proteins caspase-3 and -8 , and Bax (6). Consistently, silencing of the IncRNA MALAT1 by the microRNA (miR)-101 and miR-217 was shown to inhibit the proliferation, invasion and migration of esophageal squamous cell carcinoma cells (39).

Certain limitations in this study should be acknowledged. First, the number of included studies and the number of included patients per study was relatively small. Second, only summarized data rather than individual patient data could be abstracted. Third, we only included studies reporting HRs and survival curves; consequently, the excluded publications reporting on the prognostic value of MALAT1 may lead to bias. Fourth, the cut-off values of defining the specimens as positive or negative in terms of MALAT1 expression in cancer patients differed among these studies. Fifth, certain HRs could not be directly obtained from the primary studies, requiring calculation or extraction of the HR estimates from the survival curves. Sixth, non-original English articles were excluded from our analysis, which may also introduce bias. Therefore, additional studies with larger sample sizes, high quality, different ethnic background and same cut-off value are required to draw a more definitive conclusion.

In conclusion, increased MALAT1 expression is associated with adverse survival in several types of cancer, and MALAT1 may serve as an effective prognostic cancer biomarker. Therefore, investigating the levels of MALAT1 expression in the clinical setting is a promising approach to identifying patients who require more intimate care and may enable personalized medical follow-up.

\section{Acknowledgements}

The present study was supported by the National Natural Science Foundation of China (grant no. 81470830).

\section{References}

1. Bertone P, Stolc V, Royce TE, Rozowsky JS, Urban AE, Zhu X, Rinn JL, Tongprasit W, Samanta M, Weissman S, et al: Global identification of human transcribed sequences with genome tiling arrays. Science 306: 2242-2246, 2004.

2. Human Genome Sequencing Consortium I; International Human Genome Sequencing Consortium: Finishing the euchromatic sequence of the human genome. Nature 431: 931-945, 2004.
3. Guttman M, Donaghey J, Carey BW, Garber M, Grenier JK, Munson G, Young G, Lucas AB, Ach R, Bruhn L, et al: lincRNAs act in the circuitry controlling pluripotency and differentiation. Nature 477: 295-300, 2011.

4. Hauptman N and Glavač D: Long non-coding RNA in cancer. Int J Mol Sci 14: 4655-4669, 2013.

5. Gomes AQ, Nolasco S and Soares H: Non-coding RNAs: Multi-tasking molecules in the cell. Int J Mol Sci 14: 16010-16039, 2013.

6. Wilusz JE, Sunwoo H and Spector DL: Long noncoding RNAs: Functional surprises from the RNA world. Genes Dev 23: 1494-1504, 2009.

7. Lu KH, Li W, Liu XH, Sun M, Zhang ML, Wu WQ, Xie WP and Hou YY: Long non-coding RNA MEG3 inhibits NSCLC cells proliferation and induces apoptosis by affecting p53 expression. BMC Cancer 13: 461, 2013

8. Qiao HP, Gao WS, Huo JX and Yang ZS: Long non-coding RNA GAS5 functions as a tumor suppressor in renal cell carcinoma. Asian Pac J Cancer Prev 14: 1077-1082, 2013.

9. Schmidt LH, Spieker T, Koschmieder S, Schäffers S, Humberg J, Jungen D, Bulk E, Hascher A, Wittmer D, Marra A, et al: The long noncoding MALAT-1 RNA indicates a poor prognosis in non-small cell lung cancer and induces migration and tumor growth. J Thorac Oncol 6: 1984-1992, 2011.

10. Xu C, Yang M, Tian J, Wang X and Li Z: MALAT-1: A long non-coding RNA and its important 3 ' end functional motif in colorectal cancer metastasis. Int J Oncol 39: 169-175, 2011.

11. Ying L, Chen Q, Wang Y, Zhou Z, Huang Y and Qiu F: Upregulated MALAT-1 contributes to bladder cancer cell migration by inducing epithelial-to-mesenchymal transition. Mol Biosyst 8: 2289-2294, 2012.

12. Gutschner T, Hämmerle M, Eissmann M, Hsu J, Kim Y, Hung G, Revenko A, Arun G, Stentrup M, Gross M, et al: The noncoding RNA MALAT1 is a critical regulator of the metastasis phenotype of lung cancer cells. Cancer Res 73: 1180-1189, 2013.

13. Hutchinson JN, Ensminger AW, Clemson CM, Lynch CR, Lawrence JB and Chess A: A screen for nuclear transcripts identifies two linked noncoding RNAs associated with SC35 splicing domains. BMC Genomics 8: 39, 2007.

14. Miyagawa R, Tano K, Mizuno/R, Nakamura Y, Ijiri K, Rakwal R, Shibato J, Masuo Y, Mayeda A, Hirose T, et al: Identification of cis-and trans-acting factors involved in the localization of MALAT-1 noncoding RNA to nuclear speckles. RNA 18: 738-751, 2012.

15. Tripathi V, Ellis JD, Shen Z, Song DY, Pan Q, Watt AT, Freier SM, Bennett CF, Sharma A, Bubulya PA, et al: The nuclear-retained noncoding RNA MALAT1 regulates alternative splicing by modulating SR splicing factor phosphorylation. Mol Cell 39: 925-938, 2010

16. Yang F, Yi F, Han X, Du Q and Liang Z: MALAT-1 interacts with hnRNP C in cell cycle regulation. FEBS Lett 587: 3175-3181, 2013.

17. Tripathi V, Shen Z, Chakraborty A, Giri S, Freier SM, Wu X, Zhang Y, Gorospe M, Prasanth SG, Lal A, et al: Long noncoding RNA MALAT1 controls cell cycle progression by regulating the expression of oncogenic transcription factor B-MYB. PLoS Genet 9: e1003368, 2013.

18. Zheng HT, Shi DB, Wang YW, Li XX, Xu Y, Tripathi P, Gu WL, Cai GX and Cai SJ: High expression of lncRNA MALAT1 suggests a biomarker of poor prognosis in colorectal cancer. Int J Clin Exp Pathol 7: 3174-3181, 2014.

19. Fan Y, Shen B, Tan M, Mu X, Qin Y, Zhang F and Liu Y: TGF- $\beta$-induced upregulation of malat1 promotes bladder cancer metastasis by associating with suz12. Clin Cancer Res 20: 1531-1541, 2014.

20. Liu JH, Chen G, Dang YW, Li CJ and Luo DZ: Expression and prognostic significance of lncRNA MALAT1 in pancreatic cancer tissues. Asian Pac J Cancer Prev 15: 2971-2977, 2014.

21. Lai MC, Yang Z, Zhou L, Zhu QQ, Xie HY, Zhang F, Wu LM, Chen LM and Zheng SS: Long non-coding RNA MALAT-1 overexpression predicts tumor recurrence of hepatocellular carcinoma after liver transplantation. Med Oncol 29: 1810-1816, 2012.

22. Shen L, Chen L, Wang Y, Jiang X, Xia H and Zhuang Z: Long noncoding RNA MALAT1 promotes brain metastasis by inducing epithelial-mesenchymal transition in lung cancer. J Neurooncol 121: 101-108, 2015.

23. Pang EJ, Yang R, Fu XB and Liu YF: Overexpression of long non-coding RNA MALAT1 is correlated with clinical progression and unfavorable prognosis in pancreatic cancer. Tumour Biol 36: 2403-2407, 2015. 
24. Zhang HM, Yang FQ, Chen SJ, Che J and Zheng JH: Upregulation of long non-coding RNA MALAT1 correlates with tumor progression and poor prognosis in clear cell renal cell carcinoma. Tumour Biol 26: 2947-2955, 2015.

25. Okugawa Y, Toiyama Y, Hur K, Toden S, Saigusa S, Tanaka K, Inoue Y, Mohri Y, Kusunoki M, Boland CR, et al: Metastasis-associated long non-coding RNA drives gastric cancer development and promotes peritoneal metastasis. Carcinogenesis 35: 2731-2739, 2014

26. Ma KX, Wang HJ, Li XR, Li T, Su G, Yang P and Wu JW: Long noncoding RNA MALAT1 associates with the malignant status and poor prognosis in glioma. Tumour Biol 36: 3355-3359, 2015.

27. Stroup DF, Berlin JA, Morton SC, Olkin I, Williamson GD, Rennie D, Moher D, Becker BJ, Sipe TA and Thacker SB: Meta-analysis of observational studies in epidemiology: A proposal for reporting. Meta-analysis Of Observational Studies in Epidemiology (MOOSE) group. JAMA 283: 2008-2012, 2000.

28. Liberati A, Altman DG, Tetzlaff J, Mulrow C, Gøtzsche PC, Ioannidis JP, Clarke M, Devereaux PJ, Kleijnen J and Moher D: The PRISMA statement for reporting systematic reviews and meta-analyses of studies that evaluate health care interventions: Explanation and elaboration. Ann Intern Med 151: W65-94, 2009

29. Oremus M, Oremus C, Hall GB and McKinnon MC; ECT \& Cognition Systematic Review Team: Inter-rater and test-retest reliability of quality assessments by novice student raters using the Jadad and Newcastle-Ottawa Scales. BMJ Open 2: 2, 2012.

30. van der Molen HF, Hoonakker PL, Lehtola MM, Hsiao H, Haslam RA, Hale AR and Verbeek JH: Writing a Cochrane systematic review on preventive interventions to improve safety: The case of the construction industry. Med Lav 100: 258-267, 2009.

31. Sun M, Jin FY, Xia R, Kong R, Li JH, Xu TP, Liu YW, Zhang EB, Liu XH and De W: Decreased expression of long noncoding RNA GAS5 indicates a poor prognosis and promotes cell proliferation in gastric cancer. BMC Cancer 14: 319, 2014.
32. Necsulea A, Soumillon M, Warnefors M, Liechti A, Daish T, Zeller U, Baker JC, Grützner F and Kaessmann H: The evolution of lncRNA repertoires and expression patterns in tetrapods. Nature 505: 635-640, 2014.

33. Chen H, Xin Y, Zhou L, Huang JM, Tao L, Cheng L and Tian J: Cisplatin and paclitaxel target significant long noncoding RNAs in laryngeal squamous cell carcinoma. Med Oncol 31: 246, 2014.

34. Park JY, Lee JE, Park JB, Yoo H, Lee SH and Kim JH: Roles of long non-coding RNAs on tumorigenesis and glioma development. Brain Tumor Res Treat 2: 1-6, 2014.

35. Clemson CM, Hutchinson JN, Sara SA, Ensminger AW, Fox AH, Chess A and Lawrence JB: An architectural role for a nuclear noncoding RNA: NEAT1 RNA is essential for the structure of paraspeckles. Mol Cell 33: 717-726, 2009.

36. Dong Y, Liang G, Yuan B, Yang C, Gao R and Zhou X: MALAT1 promotes the proliferation and metastasis of osteosarcoma cells by activating the PI3K/Akt pathway. Tumour Biol 36: 1477-1486, 2015.

37. Wu XS, Wang XA, Wu WG, Hu YP, Li ML, Ding Q, Weng H, Shu YJ, Liu TY, Jiang L, et al: MALAT1 promotes the proliferation and metastasis of gallbladder cancer cells by activating the ERK/MAPK pathway. Cancer Biol Ther 15: 806-814, 2014.

38. Ji Q, Liu X, Fu X, Zhang L, Sui H, Zhou L, Sun J, Cai J, Qin J, Ren J, et al: Resveratrol inhibits invasion and metastasis of colorectal cancer cells via MALAT1 mediated Wnt/ $\beta$-catenin signal pathway. PLoS One 8: e78700, 2013.

39. Wang X, Li M, Wang Z, Han S, Tang X, Ge Y, Zhou L, Zhou C, Yuan Q and Yang M: Silencing of long noncoding RNA MALAT1 by miR-101 and miR-217 inhibits proliferation, migration, and invasion of esophageal squamous cell carcinoma cells. J Biol Chem 290: 3925-3935, 2015. 